\title{
NEW TECHNIQUE FOR OBESITY SURGERY: INTERNAL GASTRIC PLICATION TECHNIQUE USING INTRAGASTRIC SINGLE-PORT (IGS-IGP) IN EXPERIMENTAL MODEL
}

\author{
Nova técnica para a cirurgia da obesidade: Plicatura Intragástrica Single Port Intragástrico (IGS-IGP) reduz em média $51 \%$ do \\ volume gástrico em modelo experimental
}

Verena MÜLLER ${ }^{1}$, Panagiotis FIKATAS ${ }^{1}$, Safak GÜL ${ }^{1}$, Maximilian NOESSER ${ }^{1}$, Kirs ten FUEHRER ${ }^{1}$, Igor SAUER ${ }^{1}$, Johann PRATSCHKE ${ }^{1}$, Ricardo ZORRON ${ }^{1}$

From the ${ }^{1}$ Center for Innovative Surgery (ZIC), Center for Bariatric and Metabolic Surgery, Department of General, Visceral and Transplant Surgery, Campus Virchow Klinikum and Department of General, Visceral, Vascular and Thoracic Surgery, Campus Mitte, Charité-Universitätsmedizin, Berlin, Germany.

HEADINGS - Morbid obesity. Bariatric surgery. Laparoscopy. Endoscopic sleeve gastroplasty. Intragastric sleeve gastroplication
ABSTRACT - Background: Bariatric surgery is currently the most effective method to ameliorate co-morbidities as consequence of morbidly obese patients with BMI over $35 \mathrm{~kg} /$ $\mathrm{m}^{2}$. Endoscopic techniques have been developed to treat patients with mild obesity and ameliorate comorbidities, but endoscopic skills are needed, beside the costs of the devices. Aim: To report a new technique for internal gastric plication using an intragastric single port device in an experimental swine model. Methods: Twenty experiments using fresh pig cadaver stomachs in a laparoscopic trainer were performed. The procedure was performed as follow in ten pigs: 1) volume measure; 2 ) insufflation of the stomach with $\mathrm{CO}_{2} ; 3$ ) extroversion of the stomach through the simulator and installation of the single port device (Gelpoint Applied Mini) through a gastrotomy close to the pylorus; 4) performance of four intragastric handsewn 4-point sutures with Prolene 2-0, from the gastric fundus to the antrum; 5) after the performance, the residual volume was measured. Sleeve gastrectomy was also performed in further ten pigs and pre- and post-procedure gastric volume were measured. Results: The internal gastric plication technique was performed successfully in the ten swine experiments. The mean procedure time was $27 \pm 4$ min. It produced a reduction of gastric volume of a mean of $51 \%$, and sleeve gastrectomy, a mean of $90 \%$ in this swine model. Conclusion: The internal gastric plication technique using an intragastric single port device required few skills to perform, had low operative time and achieved good reduction (51\%) of gastric volume in an in vitro experimental model.

\section{Correspondência:}

Ricardo Zorron

E-mail: rzorron@gmail.com

Fonte de financiamento: não há

Conflito de interesse: não há.

Recebido para publicação: Aceito para publicação:

DESCRITORES - Obesidade mórbida. Cirurgia bariátrica. Laparoscopia. Gastroplastia vertical.
RESUMO - Racional: A cirurgia bariátrica é atualmente o método mais efetivo para melhorar as co-morbidades decorrentes da obesidade mórbida com IMC acima de $35 \mathrm{~kg} / \mathrm{m}^{2}$. Técnicas endoscópicas foram desenvolvidas para tratar pacientes com obesidade leve e melhorar as comorbidades, mas habilidades endoscópicas são necessárias, além dos custos. Objetivo: Relatar uma nova técnica para a plicatura gástrica interna utilizando um dispositivo intragástrico de portal único em modelo experimental de suínos. Métodos: Foram realizados 20 experimentos utilizando estômagos de cadáver de porco fresco em um instrutor laparoscópico. O procedimento foi realizado da seguinte forma em dez porcos: 1) medida de volume; 2) insuflação do estômago com $\mathrm{CO}_{2}$; 3 ) extroversão do estômago através do simulador e instalação do dispositivo de uma única via (Gelpoint Applied Mini) através de uma gastrotomia próxima ao piloro; 4) realização de quatro suturas de quatro pontos intragástricas com Prolene 2-0, desde o fundo gástrico até o antro; 5) medição do volume residual. A gastrectomia vertical foi também realizada em mais dez suínos e o volume gástrico pré e pós-procedimento foi medido. Resultados: A técnica de plicatura gástrica interna foi realizada com sucesso nos dez experimentos com suínos. O tempo médio do procedimento foi de $27 \pm 4$ min. Produziu redução do volume gástrico em média de $51 \%$, e a gastrectomia vertical em média de $90 \%$ neste modelo suíno. Conclusão: A técnica de plicatura gástrica interna, utilizando um dispositivo intragástrico de uma única via, exigiu poucas habilidades para ser realizada, teve baixo tempo operatório e obteve boa redução (51\%) do volume gástrico em um modelo experimental in vitro.

\section{INTRODUCTION}

$T$ he increase of obesity to one third of the world population ${ }^{1}$ calls for more than 370 million people who are currently suffering type 2 Diabetes Mellitus $(T 2 D M)^{2}$ metabolic surgery has been shown to be more effective in reducing mortality, improving hyperglycemia, hypertension and dyslipidemia in randomized clinical trials among patients with obesity and type 2 diabetes. However, surgery also has the risk for acute perioperative complications, long-term micronutrient deficiencies and psychological problems. Weighing these risks against the benefits of significant weight loss and improved glycemic control, metabolic surgery seems to be a promising treatment option for obesity-associated type 2 diabetes. However, current guidelines and treatment 
algorithms for the treatment of type 2 diabetes either ignore or underestimate the potential of metabolic surgery. In my opinion, metabolic surgery should be considered earlier in the treatment of type 2 diabetes and obesity and no longer be considered as the last therapeutic option for patients with obesity-associated type 2 diabetes.. Conservative medical treatment for obesity and/or T2DM does not seem to be successful. Multimodal therapies such as exercises, dietary change and cognitive therapy alone are little effective. Bariatric surgery is the most effective and sustainable treatment for obesity ${ }^{3}$. Roux-en-Y gastric bypass (RYGB), sleeve gastrectomy (SG), adjustable gastric banding and the biliopancreatic diversion, in combination with cognitive therapy and internal medicine, are the most successful treatment options for morbid obesity ${ }^{4}$. Endoscopic methods are recently evolving as a promising alternative for these patients. The endoscopically placed gastric balloon seems to be a safe transitional procedure for losing weight. The Apollo Overstich ${ }^{\circledR}$ is an endoscopic suturing device which has been currently used to perform gastric volume reduction in the style of the sleeve gastrectomy without resection of the stomach ${ }^{5}$. Another recent surgical procedure is the laparoscopic greater gastric curvature plication (LGCP). It is a procedure that reduces the gastric volume using sutures that invaginates the greater curvature, avoiding stapling or gastric resection, and aiming to reduce morbidity and costs for obesity surgery ${ }^{6,7}$. Although with good excess weight loss in clinical series, it still causes perioperative morbidity due to the gastric devascularisation without gastric resection.

Our group recently presented a new technique for intraluminal gastric surgery using an intragastric single port device, the IGS-IGP technique, for a series of clinical application for resection of intragastric benign tumors ${ }^{8}$. Adapting this access for IGS-IGP can potentially produce a new bariatric restrictive procedure with advantages over LGCP and the endoscopic sleeve gastroplasty.

The objective of this study was to evaluate the effectiveness of IGP in promoting gastric volume reduction in an experimental set.

\section{METHODS}

Between November and December 2015, 20 procedures were performed in the experimental surgery at our institution. The experimental model consisted of ex-vivo fresh pig cadaver stomachs installed in a laparoscopic single port trainer (Applied Medical, Rancho Santa Margarida, CA, USA) (Figures 1-3).

The procedure was performed as follows in ten pigs: 1) for measuring the initial pre-procedural gastric volume, each stomach was filled with water to a pressure of $50 \mathrm{mmHG}$ (0.06 Bar); 2) the stomach wall was then extroverted and fixed to the laparoscopic trainer single port orifice, and opened a $2 \mathrm{~cm}$ anterior incision close to the pylorus; 3 ) the single port device (Gelpoint Applied Mini, Applied Medical, Rancho Santa Margarida, CA, USA) was inserted intragastrically through the $2 \mathrm{~cm}$ gastrotomy (Figure $2 A-B$ ); 4) the lumen was insufflated inside the simulator with $\mathrm{CO} 2(1-2 \mathrm{mmHg})$, and a 30 degrees optic, a laparoscopic needle holder and a grasper were inserted through the single port; 5) four handsewing full-thickness 4-point sutures with Prolene 2-0 were performed from the fundus to the antrum in each stomach (Figure 4 A-B); 6) after finishing the procedure, the entrance defect was closed with Vicryl-0 running suture and the stomach was filled with water under pressure again and the residual volume was measured (Figure 5).

In further ten pigs, sleeve gastrectomy was performed by stapling the antrum and greater curvature over a 36F bougie. Post-procedural gastric volume was also measured. As a result of the internal plication, the technique produced macroscopic alterations in the form and capacity of the plicated stomach
(Figure 5). Plastinate models were produced filling the alterated specimens with cyanoacrylate to evaluate internal luminal anatomy for IGP and SG (Figure 6). A summary of the procedure can be reviewed in the video (video1).

\section{RESULTS}

A total of 10 internal gastric plication procedures and 10 sleeve gastrectomy procedures were performed in an ex-vivo swine cadaver stomach model. Mean total procedure time for the plications was $27 \pm 4$ min per stomach. The mean preoperative volume of the pig stomachs was $884 \mathrm{ml}(510 \mathrm{ml}-1260 \mathrm{ml})$. The mean volume after the plications was $341 \pm 169 \mathrm{ml}$. The mean volume after the sleeve gastrectomy was $63 \pm 23 \mathrm{ml}$. The mean percentage of the volume reduction for IGS was $51 \pm 25 \%$ (Table 1). The mean volume reduction after sleeve gastrectomy was $90 \pm 5 \%$. There was a high significantly difference between postoperative gastric volume, after IGP and after SG $(p<0.005)$.

TABLE 1 - Intragastric water volume measure of specimens before surgery and after IGS-IGP

\begin{tabular}{|c|c|c|c|}
\hline Pig & $\begin{array}{c}\text { Volume } \\
\text { preoperative in } \mathrm{ml}\end{array}$ & $\begin{array}{c}\text { Volume } \\
\text { postoperative in } \mathrm{ml}\end{array}$ & $\begin{array}{c}\text { Volume reduction } \\
\text { in \% }\end{array}$ \\
\hline 1 & 800 & 740 & 8 \\
\hline 2 & 610 & 420 & 31 \\
\hline 3 & 510 & 440 & 14 \\
\hline 4 & 1000 & 350 & 65 \\
\hline 5 & 1000 & 340 & 66 \\
\hline 6 & 710 & 240 & 66 \\
\hline 7 & 510 & 200 & 61 \\
\hline 8 & 510 & 250 & 51 \\
\hline 9 & 900 & 290 & 68 \\
\hline 10 & 740 & 140 & 81 \\
\hline & Mean $683 \mathrm{ml}$ & Mean 341 ml & Mean 51\% \\
\hline
\end{tabular}

Plastinate models were produced filling the lumen of procedural alterated specimens with colored cyanoacrylate to evaluate internal luminal anatomy for IGP and SG. The models showed the altered anatomy after the plication and the disposition of the remaining cavities (Figure 6).

\section{DISCUSSION}

Bariatric surgery is the most effective and sustainable treatment for obesity ${ }^{3}$. When compared with each other, certain procedures resulted in greater weight loss and improvements in comorbidities than others. Outcomes were similar between RYGB and SG, and both of these procedures had better outcomes than adjustable gastric banding. Although with optimal results in reducing weight and ameliorating co-morbidities for these patients, RYGB and SG are associated with some complications due to the technical issues of stapling and anastomosing, with a risk of leaks and fistulas reported in nearly $1 \%$ of the cases ${ }^{9}$.

New less invasive methods have been developed to promote an effective therapy without the potential problems of penetrating or resecting the gastric wall. To reduce the capacity of the stomach and allowing mechanical restriction to food intake is a known effective mechanism to promote weight loss for morbidly obese patients ${ }^{9}$. At least three current bariatric and metabolic procedures are based on gastric volume reduction, as the laparoscopic adjustable gastric banding (LAGB), SG and laparoscopic greater curvature plication (LGCP).

$\mathrm{O}^{\prime}$ Brien et al ${ }^{10}$ described a 15 year follow up for patients with adjustable gastric banding. They included 3227 patients, with a mean body mass index of $43,8 \mathrm{~kg} / \mathrm{m}^{2}$, and 714 had completed at least ten years of follow-up. They showed $47 \%$ of excess weight loss at 15 years. Angrisani et al compared the laparoscopic adjustable gastric banding with the RYGB with 51 


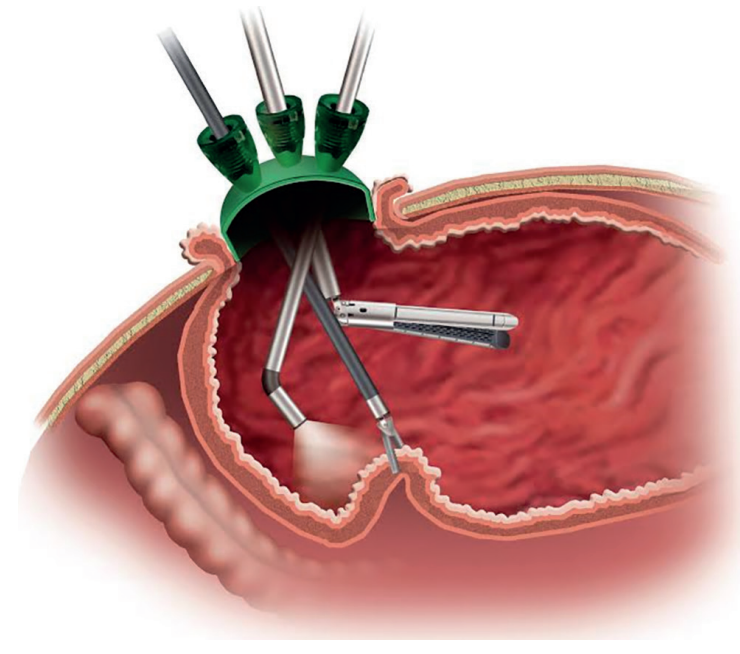

FIGURE 1 - Schematic illustration for performing IGS-IGP for gastric volume reduction as a new restrictive bariatric procedure. A single port device is inserted in the antral part of the stomach, and variable laparoscopic instruments can be inserted for intragastric surgery
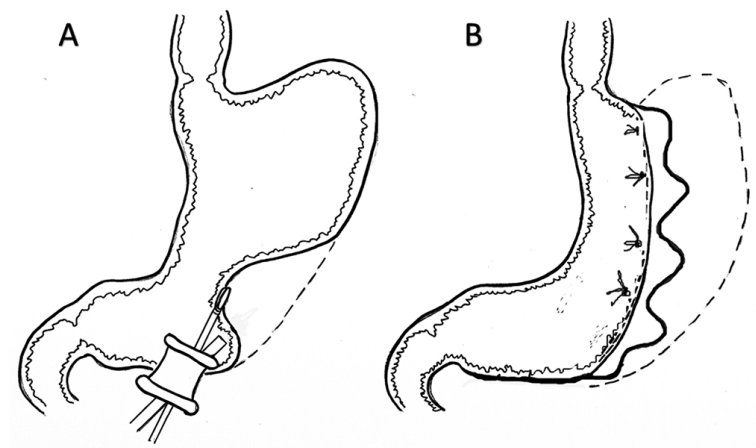

FIGURE 2 - Schematic illustration for performing IGS-IGP for gastric volume reduction in an ex-vivo experimental swine model: A) a single port device is inserted in the antral part of the stomach, and laparoscopic intragastric suturing is performed using four interrupted sutures; B) intragastric greater curvature plication is started from the fundus region, progressing with further non-absorbable sutures to the antrum and, finally, the entry incision is closed with running suture

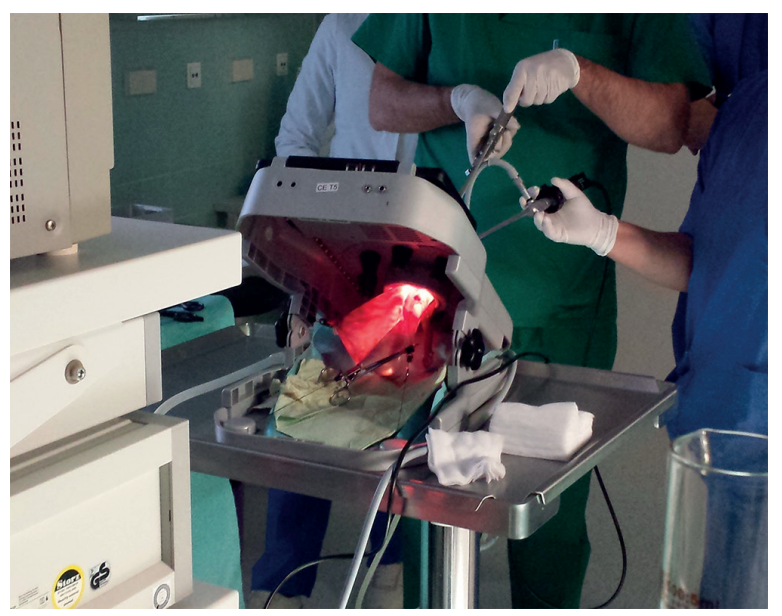

FIGURE 3 - External view and team position at laparoscopic trainer for single port intragastric surgery (IGS) for internal sleeve plication

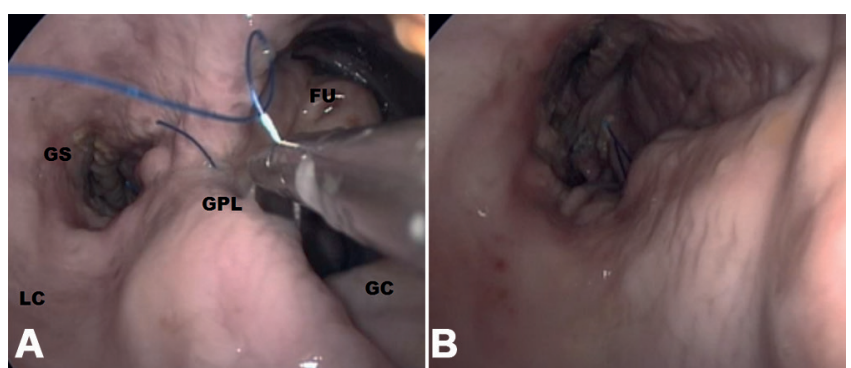

FIGURE 4 - A) Internal laparoscopic view after the first suture performed at the gastric fundus (FU) and the resulting gastric sleeve tubular anatomy (GS) is shown, as the gastric suture plication (GPL) is performed along the greater curvature (GC), leaving the lesser curvature (LC) intact; B) final aspect of gastric reduction and altered anatomy by intragastric greater curvature plication

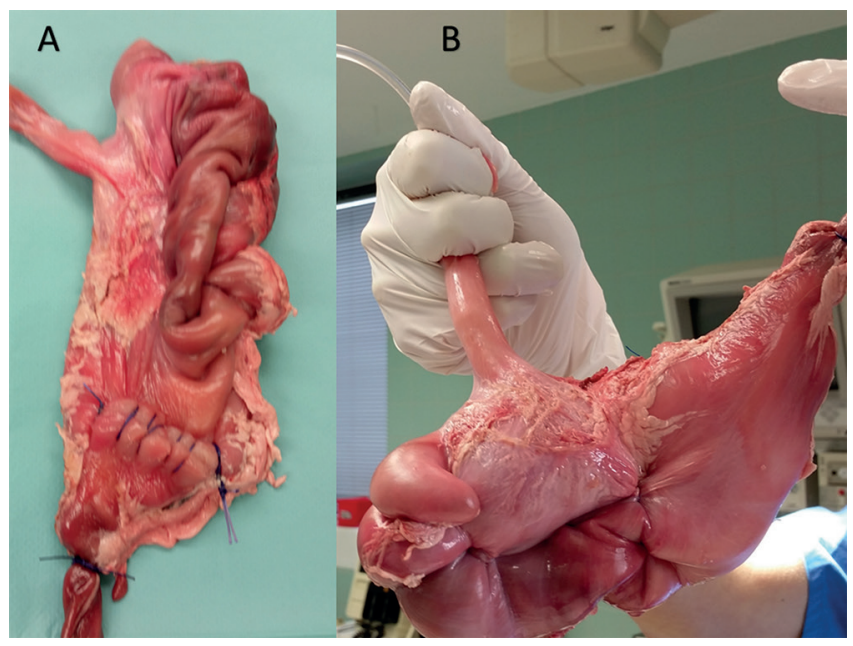

FIGURE 5 - A) Final external aspect after concluding IGS internal sleeve plication; $B$ ) measuring the gastric volume after the anatomical modification, filling the stomach with high pressured $(50 \mathrm{mmHg})$ of water

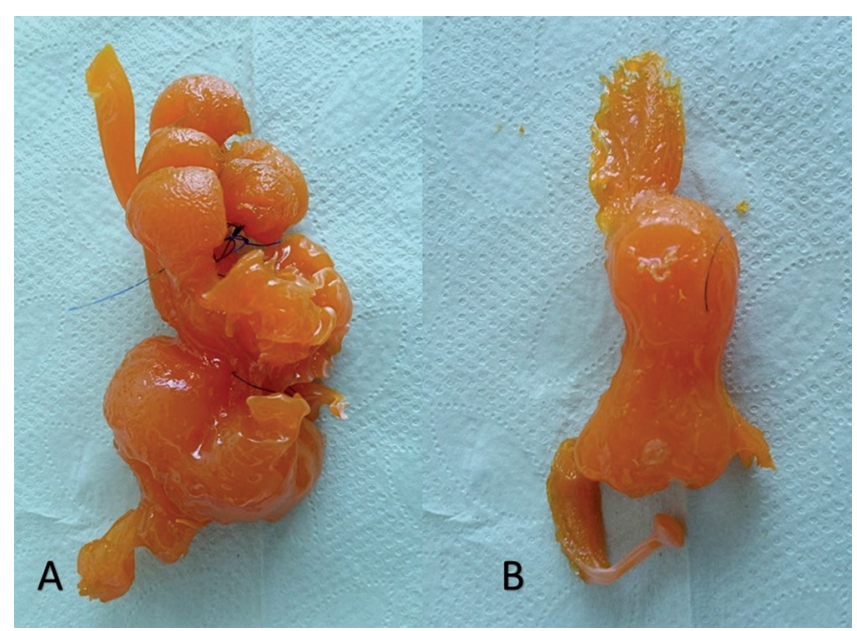

FIGURE 6 - Plastinate model with cyanoacrylate showing differences in postoperative anatomy after IGSIGP (A) and sleeve gastrectomy (B) 
patients in a period of five years ${ }^{11}$. Mean BMI before surgery was $43 \mathrm{~kg} / \mathrm{m}^{2}$. The mean BMl at 12 months after surgery was 35 for the RYGB and 39 for the LAGB, decreasing to 29 for the RYGB and 36 for the LAGB after three years and staying the same for the RYGB at 29 and still decreasing for the LAGB at 35 after five years. Excess weight loss was significantly higher in the RYGB group after five years (67\% RYGB and 48\% LAGB). Himpens et $\mathrm{al}^{12}$ showed an excess weight loss of $73 \%$ three years after and $58 \%$ six years after SG, similar to the findings of Diamantis et al ${ }^{13}$, with an EWL of $62 \%$ at five years after and $54 \%$ at six years after SG.

Talebpour et al shared their 12 years experience in 800 patients submitted to $\mathrm{LGCP}^{14}$. The mean $\mathrm{BMI}$ of their patients was $42 \mathrm{~kg} / \mathrm{m}^{2}$; the mean EWL was $20 \%$ after one month $(n=779)$, $67 \%$ after 12 months $(n=491), 70 \%$ after 24 months $(n=356), 66 \%$ after three years $(n=251), 62 \%$ after four years $(n=176)$ and $55 \%$ after five years $(n=134)$ following surgery. Severe complications occurred in $1 \%$ of the patients, including gastric necrosis and enteric fistulae. They had to perform operative revisions because of regain in 32 cases and failure in six cases. These findings show in the literature similar effects in EWL of LGCP to the SG ${ }^{13,15}$. In a systematic review, the complication rate of the LGCP seems to be higher ${ }^{16}$. There were minor complications with a rate of $11 \%$, such as nausea and vomiting and major complications including bleeding, leaks, gastric obstruction and gastric fistula in $4 \%$. Still, the procedure has not gained much popularity due to the possibility of these complications, compared to the low rates in the literature for RYGB or SG.

Endoscopic alternatives were developed to fill the gap between bariatric procedures with high effectiveness but with more complications, and the conservative therapy, less harmful but less efficient in obtaining sustainable weight loss. The endoscopically placed gastric balloon seems to be a safe procedure for losing weight, but a metanalysis showed that it is only a short-term effective treatment, but it is not yet capable to maintain a weight loss over a long period of time $^{17}$. However, this therapy only seems to be successful in very compliant patients and weight regain after removal of the balloon is common ${ }^{17-20}$.

The novel endoscopic suturing device available in the market, Apollo Overstich ${ }^{\circledR}$, has been currently used to perform a gastric volume reduction in the style of the SG without resection of the stomach ${ }^{5}$. Abu Dayyeh et al used this device in 2013 in four patients with a mean BMI of $36 \mathrm{~kg} / \mathrm{m}^{2}$. The procedure time was 172 to 245 min and they placed 26 sutures $^{5}$. Lopez-Nava et al used the Apollo overstitch as well in 50 patients ${ }^{21}$. The mean procedure time was $66 \mathrm{~min}$ and they placed seven sutures on average with five stitches in each suture. They did not measure the volume of the stomach pre- and post-intervention. Oral contrast studies in addition with an endoscopy were optional for the patients at $24 \mathrm{~h}$, three and six months. The mean BMI changed from $37.7 \pm 4,6 \mathrm{~kg} / \mathrm{m}^{2}$ to $30.9 \pm 5,1 \mathrm{~kg} / \mathrm{m}^{2}$ at one year follow up. The indication of this therapy is currently applied to low-BMI patients ${ }^{5,21,22}$, but indication for superobese as a first step procedure for a $2^{\text {nd }}$ stage strategy is recently described ${ }^{23,24}$. The technique seems promising, but long-term results and studies with larger series are needed to evaluate the effectiveness of this method in the morbidly obese population.

The physiology of our proposed IGP technique is potentially similar to the endoscopic gastric plication and not similar to the laparoscopic gastric plication, where the greater curvature is denervated and devascularized, and the plicated stomach wall is compressed to the lumen. In IGP, there is rather a delaying in gastric emptying caused by the shortening of the stomach and the impaired motility due to the sutures. In fact, in a recent study evaluating postoperative scintigraphic findings on patients submitted to endoscopic sleeve gastroplasty, Abu Dayyeh reported a delayed gastric emptying, recognizing a complete different mechanism of action of this therapy, if compared with $\mathrm{SG}$, where on the contrary a rapid gastric emptying is expected ${ }^{25}$.
The results of our study show that the IGP-IGS technique is feasible and produces, ex-vivo, a significant reduction in the gastric volume by restricting its area of distension. It is possible to reduce the volume of the stomach without resecting or bypassing it. It is also possible to perform a surgical gastric plication without devascularization, by acting intraluminally. The entry wound in the antral region does not produces relevant morbidity in our clinical experience with IGS for resection of intragastric tumors. In studies, LGCP seems to be as effective as the sleeve gastrectomy regarding EWL and ameliorating comorbidities. The IGP-IGS can potentially be as effective as that with less operative time, as there is no need to entry the rest of the peritoneal cavity nor to liberate the gastric vessels or vessel ligation. Leaks, gastric necrosis or bleeding are improbable, as the technique does not induce gastric ischemia. A shorter learning curve is expected, it is a procedure with only one incision and only one technical step. It also is reversible by just cutting the suture lines, endoscopically, within the first weeks after the operation. As the endoscopic similar technique - endoscopic sleeve gastroplasty - it can be followed by surgical malabsorptive methods as a second stage operation in cases with insufficient weight loss without any change to previous surgery.

Survival studies have to be addressed to evaluate the feasibility and safety of the technique.

\section{CONCLUSION}

The consequences of this study cannot be applied yet in the clinical practice, as experimental survival studies are needed to prove the feasibility and safety of IGP. Its evaluation as a valuable method for therapy of morbid obesity, in achieving sustainable weight loss, is the next step of our research.

\section{ACKNOWLEDGEMENTS}

The authors thank Applied Medical Germany for their research support providing simulators and disposable materials.

\section{REFERENCES}

1. Ng M, Fleming $T$, Robinson $M$, et al. Global, regional, and national prevalence of overweight and obesity in children and adults during 1980-2013: a systematic analysis for the Global Burden of Disease Study 2013. Lancet. 2014;6736(14):1-16.

2. Blüher M. [Insulin or surgery? :The perspective of a diabetologist]. Chirurg 2014;85(11):957-962.

3.CarlssonLMS, PeltonenM,AhlinS, etal.BariatricSurgeryandPreventionofType 2DiabetesinSwedishObeseSubjects. NEnglJMed.2012;367(8):695-704

4. Schauer PR, Kashyap SR, Wolski K, et al. Bariatric Surgery versus Intensive Medical Therapy in Obese Patients with Diabetes. N Engl J Med. 2012:366(17):1567-1576.

5. Abu Dayyeh BK, Rajan E, Gostout CJ. Endoscopic sleeve gastroplasty: a potential endoscopic alternative to surgical sleeve gastrectomy for treatment of obesity. Gastrointest Endosc. 2013;78(3):530-535.

6. Bradnova O, Kyrou I, Hainer V, et al. Laparoscopic Greater Curvature Plication in Morbidly Obese Women with Type 2 Diabetes: Effects on Glucose Homeostasis, Postprandial Triglyceridemia and Selected Gut Hormones. Obes Surg. 2014;24(5):718-726.

7. Fried M, Dolezalova K, Buchwald JN, McGlennon TW, Sramkova P, Ribaric G.Laparoscopicgreatercurvatureplication(LGCP)fortreatmentofmorbid obesity in a series of 244 patients. Obes Surg. 2012;22(8):1298-1307.

8.Intragastrische (IGS) Single-Port-Chirurgie bei großen gutartigen Magentumoren. R Zorron, C Bothe, M Holtmann, T Junghans. Zeitschrift für Gastroenterologie 53 (08), KC096

9. Laparoscopic greater curvature plication: initial results of an alternative restrictive bariatric procedure. Ramos A, Galvao Neto M, Galvao M, Evangelista LF, Campos JM, Ferraz A. Obes Surg. 2010 Jul;20(7):913-8.

10. O'Brien PE, MacDonald L, Anderson M, Brennan L, Brown W. Long-term outcomes after bariatric surgery: fifteen-year follow-up of adjustable gastric banding and a systematic review of the bariatric surgical literature. Ann Surg. 2013;257(1):87-94. 
11. Angrisani L, Lorenzo M, Borrelli V. Laparoscopic adjustable gastric banding versus Roux-en-Y gastric bypass: 5-year results of a prospective randomized trial. Surg Obes Relat Dis. 2007;3(2):127-132.

12. Himpens J, Dobbeleir J, Peeters G. Long-term results of laparoscopic sleeve gastrectomy for obesity. Ann Surg. 2010;252(2):319-324.

13. Diamantis $T$, Apostolou KG, Alexandrou A, Griniatsos J, Felekouras $E_{\text {, }}$ Tsigris C. Review of long-term weight loss results after laparoscopic sleeve gastrectomy. Surg Obes Relat Dis. 2014;10(1):177-183.

14. Talebpour M, Kalantar Motamedi HM, Talebpour A, Vahidi H. Twelve year experience of laparoscopic gastric plication in morbid obesity: development of the technique and patient outcomes. Ann Surg Innov Res. 2012;6(1):7.

15.Chouillard E, Schoucair N, Alsabah S, Alkandari B. Laparoscopic Gastric Plication ( LGP ) as an Alternative to Laparoscopic Sleeve Gastrectomy ( LSG ) in Patients with Morbid Obesity: A Preliminary, Short-Term , Case-Control Study. 2015:4-9.

16. JiY, Wang Y, Zhu J, Shen D. A systematic review of gastric plication for the treatment of obesity. Surg Obes Relat Dis. 2014 Nov-Dec;10(6):1226-32.

17. Imaz I, Martínez-Cervell C, García-Álvarez EE, Sendra-Gutiérrez JM González-Enríquez J. Safety and effectiveness of the intragastric balloon for obesity. A meta-analysis. Obes Surg. 2008;18(7):841-846.

18. Roman S, Napoléon B, Mion F, etal. Intragastric balloon for "non-morbid" obesity: A retrospective evaluation of tolerance and efficacy. Obes Surg 2004;14(4):539-544.
19.Yasawy M, Al-Quorain A, Hussameddin A, Al-Sulaiman R, Yasawy Z. Obesity and gastric balloon. J Fam Community Med. 2014;21(3):196

20. Milone L, Strong V, Gagner M. Laparoscopic sleeve gastrectomy is superior to endoscopic intragastric balloon as a first stage procedure for super-obese patients (BMI \pm 50 ). Obes Surg. 2005;15:612-617.

21. Lopez-Nava G, Galvão MP, Bautista-Castaño I, Jimenez-Baños A, Fernandez-Corbelle JP. Endoscopic Sleeve Gastroplasty: How I Do It? Obes Surg. 2015;25(8):1534-1538. doi:10.1007/s11695-015-1714-7.

22.Galvao MP, Grecco E, Souza TF, Quadros LG, Silva LB, Campos JM Endoscopic sleeve gastroplasty- minnimally invasive therapy for primary obesity treatment. ABCD Arch Bras Cir Dig 2016; 29 (1): 95-97.

23. Sharaiha RZ, Kedia P, Kumta N, DeFilippis EM, Gaidhane M, Shukla A, Aronne LJ, Kahaleh M. Initial experience with endoscopic sleeve gastroplasty: technical success and reproducibility in the bariatric population. Endoscopy 2015; 47: 164-166.

24. Zorron R, Galvão-Neto MP Campos J, Branco AJ Sampaio J, Junghans T, Bothe C, Benzing C, Krenzien F., From Complex Evolving to Simple: CurrentRevisionalandEndoscopicProceduresfollowingBariatricSurgery, Arq Bras Cir Dig. 2016; 29(1):128-133.

25. Abu Dayyeh BK, Acosta A, Camilleri M, Mundi MS, Rajan E, Topazian MD, GostoutCJ. Endoscopic sleeve gastroplasty alters gastric physiology and induces loss of body weight in obese individuals. Clin Gastroenterol Hepatol. 2015 Dec 31. pii: S1542-3565(15)01714-0. doi: 10.1016/j. cgh.2015.12.030. [Epub ahead of print] PMID:26748219 